\title{
Cultural Logic of Dictionary-Making: An Analysis Based on Hermann Gundert's Dictionary
}

ANOOP V.

\begin{abstract}
Modern lexicography argues that apart from a compilation of words, there is a cultural discourse in the dictionary. From the premises of this argument, this paper explores the cultural logic of Gundert's dictionary which was created during the missionary period. The first part of this paper tries to explain the functions of dictionary and how it becomes political in the contemporary knowledge discourse. After a general introduction of dictionaries in Malayalam, this paper analyses the Gundert's dictionary. The paper proposes that Gundert's dictionary, which was described as that which uses scientific methodology and comprehensive analysis, also carries the temperament of colonial sensitivity.
\end{abstract}

Key words: Cultural logic, Cultural discourse, Ideology, Scientific methodology, Missionary literature, Colonial discourse

Dictionary is not only a compilation and definition of words, it is accepted that there is a cultural discourse in the dictionary. A dictionary is said to be 'a book dealing with words of language so as to set forth their orthography, pronunciation, signification and use, their synonyms, derivations and history or at least some of these.' The commonly recognized categorizations of dictionaries based on the number of languages used, like monolingual, bilingual, multilingual etc. which signifies differences in space, time and culture, is the basis of this study.

Lexicography discusses not only the formal explanations, but also all the facets of its creation. The most important one is the historical background of the creation of the dictionary and to 
whom it addresses. As it is relevant in the process of writing of the dictionary, it becomes relevant in lexicography also. Many studies have been conducted regarding the function of dictionaries and to whom it addresses. Mc David, while discussing the functions of dictionary summarises as follows:-

1. To scholars, in all probability the most important aspect of a dictionary is to record the language whether a diachronic statement of the development of words and meanings from their records to the present, or the ordering of them in contemporary context, sequences or centrality of meaning ...

2. Another aspect of the dictionary is acquainting a user with a language, or the variety of a language other than his own ...

3. A third function is to supply incidental information, linguistic or otherwise, for the casual user...

4. Finally, there is the role of a reference book...a guide to what one should do and especially what one should not do.

(Bejoint 2000:108)

This explains that there are indications of a language and culture expressed along with the history of the place. It also deals with a receptor, which the dictionary addresses. It is generally observed that dictionary has one or more distinguished functions.

The decision concerning the purpose or purposes of a planned dictionary is the most important one. A good part of both scientific and the commercial successes of the dictionary will be the result of how reasonably this dictionary was made, and how adroitly it was carried out (Bejoint 2000: 109).

Apart from that, Hartmann while discussing about the functions of dictionary makes the argument further on the politico- 
cultural process involved in the production of a dictionary in his book The Dictionary as an Ideological Weapon (Bejoint 2000:109). The assumption that the ideological function of dictionary and the politics involved, opens up the possibilities of lexicography of different periods.

The genealogy of dictionary is divided into monolingual or bilingual based on the number of languages used. Monolingual dictionary tries to give the meanings of words and to explore the possibilities of its uses through examples in the same language. On the contrary, bilingual or multilingual dictionaries, apart from defining the meaning, try to transcend the meaning to a different cultural context and translate it to a different linguistic possibility. Thus it must be stated that, the words which are documented, would carry with it, the socio-historical contexts of which it is a part of. When the word which carries contradictions is collected in a dictionary with its meanings, dictionary has its limits in containing the contradictions. It becomes more complicated, when the meaning is explained (in bilingual dictionaries) in a distinctive linguistic and cultural context.

A study of different functions and genres of dictionary, demands a cultural critique rather than a linguistic analysis. The dictionary movement which began with the missionary period in Kerala as a part of religious activities, and the general characteristics that it shares, studied in relation to Gundert's dictionary is the significance of the study.

The history of dictionary- making as distinct from koshagrandham of ancient India traces back to the 17th century. Though many of the early dictionaries are not available now, some of them are available in the form of extracts reproduced elsewhere. Those dictionaries which were written for the students of the seminary were incomplete too. Arnose Pathiri (1715-1789), Stephan 
Pathiri (1700- 1769), Clement Peeyaniyus (1714- 1782), Farose Pathiri (1715-1789) and others did much work during this period. Four dictionaries were published from Varapuzha, between 1860 and 1890. It can thus be observed that, these served as a model to later lexicographers like Gundert and his successors.

Later, it is evident that the state also encouraged the dictionary-making by the foreign missionaries. A Dictionary of High and Colloquial Malayalam and English by Benjamin Bailey is considered as the first dictionary in Malayalam. When this dictionary was published in 1846, the then King of Travancore province Swathi Thirunal offered a good reward with cash to the lexicographer. As a mark of reverence, Bailey dedicated his dictionary to His Highness, for the encouragement which he gave to the Malayalam language and literature (Vareet 1973: 143). This dictionary which is as good as Gundert's with regard to the collection of vocabulary and the explanation of meaning, is considered low for its unlimited usage of Sanskrit words and such other things. On the other hand, scholars like C.L Antony, points out that Bailey's dictionary like that of Gundert's, apart from making a historiography of language, was formed anticipating the contemporary linguistic possibilities.

Gundert's Malayalam- English dictionary is the earliest dictionary of Malayalam language, which is prepared in a scientific manner and attained acclaim in scholarly discussions. Along with being helpful to the missionaries, the pain and care that the lexicographer had taken in the collection of words and its arrangement is well commended. P. K Parameswaran Nair observes that, the categorization of dictionary 'provides the pronunciation, origin and etymology of each word and its synonyms in other languages. It also rationally traces its ancient meaning and its evolutions and its rhetoric and logic. The linguistic variations of each word, its phrases and other words where it is used as a prefix are arranged under the same word. These methods have been adopted from modern western dictionaries, and could not be found in Malayalam dictionaries' (Samuel 1975: 20). Later, scholars have noted the explanations of the 
descriptions on the word.

The study of Cheriyan Kuniyanthodath, on Gundert's dictionary, explaining sequential arrangement of words in alphabetical order, pronunciation in roman script, distinct and new grammatical explanation, meaning in English, Malayalam equivalent, numbering different meaning, ancient usage, references from ancient texts, idioms, proverbs, shows the very scientificity of the text (Cheriyan 1997: 48-49).

The important part of this dictionary is the words in it. In the introduction to the dictionary, Gundert speaks of the different sources in collecting words for the dictionary. 'The words have been taken from all the available sources, from the lips of the speakers, castes and occupations, from the letters of and records of districts and writers in prose and poetry of every age' (Gundert). From this, we can note that he had taken proverbs from day-to-day discourses, caste and dialect variations, official documents, literary works of different periods, etc. for making the dictionary. He has put his effort on giving the usage and reference, as the meaning changes according to the method used. Those quotations have been considered as the peculiarity of his dictionary.

On the methodology that Gundert used for the making of his dictionary, Moorkoth Kumaran states: 'the work was done while residing at Thalassery and Ellikunnu. It was said that he used to write down words directly from the conversations and letters of people of different ranks, caste and religion. It is also known that Gundert used to ask the people whom he sees on his way about the names of those herbs and leaves which he had collected on his evening walk. He went to the work places of blacksmith, goldsmith and carpenter to learn the names of their instruments.

He collected words not only from literary works, but also from official government documents. The joining of members of different castes, from Brahmins to Harijans, in the Basal mission, 
helped him more, to collect different words and also to understand the linguistic differences (Vareet 1973: 36). In this way, by utilizing every possibilities of vocabulary collection, he created a dictionary which represents the period. This has won him appreciation:

1. "He was a linguist, a historian, a folklorist, sociologist and probably many more things. It was the versatility that made him an unusually competent lexicographer" (Nair 1975 : 168).

2. "He is famous for a systematic, scientific approach to cultural phenomena. So he is praised as a pioneer of disciplines like Kerala History and Malayalam folklore" (Sacria and Frens 1993: 15).

Regarding the methodology used in his dictionary, Gundert explains, 'the arrangement chosen has been to point out as far as possible the root and the origin of each word, to give first, its primitive sense and to add figurative and free senses in rational order; examples taken from reliable authorities are also added' (Cherian 1997: 48/49). An examination of this new methodology drives us to different inquiries on the cultural logic of the reception, application and illustrations. The question here is whether the peculiarities attributed to the Gundert's dictionaries like diversity of resources, historical significations, idioms and proverbs are merely for being scientific propinquity or whether it is different position that the dictionary creates standing away from the general spirit of the missionary period is a crucial point of enquiry.

The analysis of the methodology of Gundert's dictionary shows that the main characteristics that moulded its scientificity, can be listed as follows:

The method that has been adopted in the organization and scripting of alphabet. 
The analysis of the assumptions of the origin of Malayalam language in which the dictionary based itself.

Diversities of the sources that it relied. For example:conversations. Official documents, colloquial usages etc.

The examples, historical documents, proverbs and idioms that have been given in the explanations.

Thus, an exploration of the cultural logic of this scientific methodology ultimately leads us towards the cultural context of the age. The features of the methodology of Gundert's dictionary are very much influenced by the contemporary context. For Raghava Warrier, "those styles in his works are not to be studied merely as an opinion of an individual. He observes that, those descriptions that have been recurring in different works, should be considered as inscriptions of the reflections of a community, politics and representative of world view of the age and must attempt to resist it (Raghavawarrier 2006: 136). For that reason, the peculiarities of his dictionary should be read in the general background of the literary/ non-literary activities of the missionaries of the age.

Many publications have come out in the background of the history of missionary activities in Kerala. The introduction of printing, enlightenment and education have welcomed and supported the production of these works. Apart from religious scholarships, language was an area of study. Many dictionaries and the books on grammar were created in that account. While examining the writings of the missionaries in Malayalam, it is evident that they have taken tremendous effort and interest in studying and recording the Kerala history and culture. The most secular writings were historical writings which pooled great interest making a history for the colonized and also demarcated their subjectivity. For that, they had collected and later published many historical documents and creeds. Scaria Zcharia observes "keralothpathi" and "keralapazhama" written by Gundert and Paulius' text demonstrates the historicizing tendency of the period (Sacria and Frens 1993: 28) 
Along with the process of historicizing, the study of folklore was also established. Many studies were done collecting and compiling the discourses of the commoners. eg: A Collection of Malayalam Proverbs by Polinus (1791), Critical Edition of Keralothpathi by Gundert (1843), Pazhanjollumala by Gundert (1845) are some of them.

The works that are explained above were landmarks in the language history and grammar of Malayalam. But, the knowledge that it models is an important point of study. The propriety and observation skill that it upholds is a serious issue to be addressed. It includes narratives about the past, historical books and proverbs which establishes the moral and judicial institutions of the society. While explaining the meanings based on these texts and placing examples, Gundert's dictionary also posits a continuation of the world view and its logic which is presented in those texts.

We can add many examples from Gundert's dictionary on this. This dictionary also contains certain words which marks the knowledge system of Kerala/ India, but that which is not a part of the common discourse. If we examine the words, "akkapadam", "odi", we can understand that, he had done justice to the missionary/ folklore texts that we have mentioned earlier. If we closely examine the similar customs among Brahmins, we can understand the politics of this duality. The examples like: for the word 'asuran', he notes that 'chekavar' is of asura clan, and for the word 'aparadham' he notes "antharjanam has aparadham of puthusseri moos", directs us to the race and gender discrimination. It is not accidental that we see such explanations and words in that dictionary.

Accepting the authority and scientific temperament of Gundert's dictionary, we must admit that the above mentioned methodology refutes the assumption that lexicographer as an apolitical individual. Conversely, it presents the world view and political readings of missionary activities of that time. The inherent novelty of the structure, which is considered as the fundamental peculiarity of Gundert's dictionary, is a part of missionary period. 
Raghava Warrier quotes Edward W. Said while studying such tendencies in Gundert's works, "along with the process of colonization and imperialism, there have been various occidental discourses on orient like India and their cultures. Those portrayals which are drawn from geographical descriptions, historical narratives, literature, from the period of enlightenment, worked for controlling or manipulating the oriental cultures and occidentals. It was a colonial discourse of the West through teaching and learning, explaining, critiquing and evaluating. Various discourses have been established in religion, morality, science, history, cosmopolitanism, world view, individual qualities, ethnic nature etc. in this concern" (Raghavawarrier 2006: 137).

The methodology of Gundert's dictionary can be established further based on the nature of the descriptions. This thesis tries to establish the scientific attitude and authenticity, which are considered as the peculiarities of Gundert's dictionary is not discarded from the context on the contrary, it was derived from the missionary literatures of the time. The logic of this methodology opens up possibilities in cultural studies. It also submits itself to further explorations in lexicography.

\section{NOTES}

1. Malayalam- Latin, Latin- Malayalam, English- Malayalam, Malayalam- English-Latin are the dictionaries published from Varapuzha (Samuel 17).

2. "To specify, if Gundert's dictionary is analytical and scientific, Beily's is integrated and aesthetic" (Antony 68). C.L Antony derives such a conclusion from the assumption that Beily's dictionary vary from that of Gundert's in the exploration of possibilities of the language in use.

3. The credit foe illustrating, for the first time in the history of Malayalam lexicography, the usages of words with quotations from Malayalam works (Kunjanpillai 175). 


\section{REFERENCES}

Anand, 2009. Ezhuth: Pusthakam Muthal Yudham Vare [Writing:From Text to War]. Kottayam: D.C Books, Print.

Antony, C.L.,1980. Bhashapadanangal Randam Bhagam [Studies on Language 2nd Part] Kottayam: National Book Stall, Print.

Bejoint, Henry, 2000. Modern Lexicography: An Introduction New York: OUP, Print.

Gundert, Hermann, 1995. Gundert Nikhandu [Gundert's Dictionary]'. Kottayam: D.C Books, Print.

Joseph, Deepa Mary, 2010. "Gundert Nikhanduvum Samoohavum" Bhasha Naveena Padanavazhikal [New Studies in Language]. Ed, Sibu Modayil. Aluva: Vidvan P.G Smaraka Gaveshana Kedram, U.C College, Print.

Kuniyanthodath, Cherian, 1997. Malayalabhashayum Gundertum [Malayalam Language and Gundert] Calicut: P.K Brothers, Print.

Kunjanpillai, Sooranad. "Nikhandu Nirmanam: Vibhinna Mathrukakal." ["Different Models of Dictionary Making"] Bhashaposhini. Kottayam: Malayala Manorama, Oct-Nov 1984. Print.

Misra, B.G, ed. 1980, Lexicography in India. Mysore: Central Institute of Indian Languages, Print.

Nair, S. Guptan, comp. 1997. Dr.Godavarmmayude Prabandhangal [Essays of Dr.Godavarmma]'. Trivandrum: Kerala Bhasha Institute,. Print.

"Pusthakangal, Pusthakavilpanakar, Grandhashalakal, Nikhandukal, Yudhangal" ["Books, Book sellers, Libraries, Dictionaries, Wars"]. Bhashaposhini. Kottayam: Malayala Manorama, March 2007. Print. 
Purushothaman, M.M. "Nikhandu Nirmanathile Missionary marude Sambhavana." ["Contribution of Missionaries in Dictionary Making”]. Bhashaposhini. Kottayam: Malayala Manorama, 1984 Oct- Nov. Print.

Rahgavawarrier, M.R, 2006. Ammavazhikeralam [Matrilineal Keralam]. Trichur: Kerala Sahitya Academy, Print.

Sacria, Zcharia and Albrecht Frens eds. 1993. Dr. Hermann Gundert and Malayalam Langugage, Changanassery: Centre for Kerala Studies,. Print.

Samuel, Chandanappalli, comp., 1975. Missionary Malayala gadya Mathrukakal [Models of Prose in Missionary Malayalam] Kottayam: National Book Stall,. Print.

Vareet, K. P., 1973. Dr. Hermann Gundert, Kottayam: National Book Stall, Print.

(Translation of the paper nikhandu nirmmithiyile sa:mska:rika yukti - gundertinte nikhanduvine munnirthiyulla vishakalanam presented in the seminar Growth of Malayalam Language and the Role of Knowledge Text Translation on January 29, 2011.) 